\title{
Maternal morbidity in emergency lower segment cesarean section
}

\author{
P. Kalpana ${ }^{1 *}$, T. Praveena ${ }^{2}$
}

\author{
${ }^{1}$ Department of Obstetrics and Gynecology, Malla Reddy Medical College for Women, Suraram, Hyderabad, \\ Telangana, India \\ ${ }^{2}$ Consultant Gynecologist, Baby’s Life Hospital, Hanamkonda, Warangal, Telangana, India
}

Received: 20 May 2019

Accepted: 05 June 2019

\author{
*Correspondence: \\ Dr. P. Kalpana, \\ E-mail: kalpanapreddy67@gmail.com
}

Copyright: () the author(s), publisher and licensee Medip Academy. This is an open-access article distributed under the terms of the Creative Commons Attribution Non-Commercial License, which permits unrestricted non-commercial use, distribution, and reproduction in any medium, provided the original work is properly cited.

\section{ABSTRACT}

Background: With a steep fall in maternal mortality and morbidity and with much more liberalization of indications, the incidence of cesarean section rate has greatly increased over the last thirty years and almost doubled in the current decade. The objective of this study was to study incidence of maternal morbidity in emergency lower segment cesarean section.

Methods: Hospital based prospective study was carried out among 200 women undergoing emergency lower segment cesarean section. Data relating to demographic characteristics, clinical characteristics, maternal and fetal indications, incidence of morbidity, and types of morbidities, Intra operative complications, and Post operative complications was noted down. Chi square and odds ratio was used for statistical analysis.

Results: The incidence of LSCS was $24.21 \%$. Incidence of emergency LSCS was $96.74 \% .71 \%$ were having primary LSCS and $20.5 \%$ were booked cases. The most common maternal indication for emergency LSCS was pregnancy induced hypertension and eclampsia in $32.5 \%$ of the cases. The most common fetal indication for emergency LSCS was fetal distress in $60 \%$. Incidence of morbidity was $35 \%$ and it was associated with booking status, parity and social class. Incidence of intraoperative complications was $23.5 \%$. Majority $(18.5 \%)$ developed febrile morbidity followed by wound sepsis in $12.5 \%$, urinary tract infection in $8 \%$, mastitis in $7.5 \%$, respiratory tract infection in $7 \%$, wound gaping in $4 \%$, paralytic ileus in $3 \%$, endometritis in $2.5 \%$, postpartum hemorrhage in $1.5 \%$, 2 cases of burst abdomen and one case of small bowel obstruction.

Conclusions: Emergency LSCS was more common than elective LSCS and it was associated with booking status, parity and social class.

Keywords: Emergency, Lower segment cesarean section, Incidence, Maternal morbidity

\section{INTRODUCTION}

Cesarean delivery is defined as the birth of a fetus through an incision in the abdominal wall and uterine wall. Cesarean section is an ancient obstetric operation. Cesarean section the abdominal delivery of a fetus, whenever indicated, either in maternal or fetal interest or both is the most important tool in the obstetrician's armamentarium. It is done either as elective or emergency surgery. The rate of cesarean deliveries increased in recent years, reasons are technological monitoring of labor increased the chances of detecting fetal distress, breech presentation or prolonged labor beyond 18-24 hours may require intervention, forceps deliveries are less likely to be attempted because of high risk to fetus, elderly primis are at greater risk of complications in vaginal delivery and dystocia. ${ }^{1}$

Until the early half of this century, both maternal and perinatal mortality and morbidity were very high after 
cesarean section, mainly because of hemorrhage and sepsis. There has been drastic fall in both maternal and perinatal mortality and morbidity after cesarean section in the recent times, consequent on the dawn of the factors like rapid changes and new discoveries in surgical skills and techniques, advanced anesthetic techniques, improved and modernized neonatal and premature care facilities, newer methods for early recognition of fetal distress, thereby saving babies well before serious compromise occurs, advent of higher and most potent antibiotics, availability of blood transfusion facilities. Inspite of all these improvement in medical care, there is still comparatively higher rate of maternal and perinatal mortality after cesarean section, especially when it is contemplated as emergency surgery, where the indication for section is either maternal or fetal complication itself. ${ }^{2}$

In developing countries like India, due to illiteracy, lack of health education and low socio-economic status, majority of antenatal cases will be un-booked without any regular checkups. In addition to that there is inadequacy of health care facilities and transport facilities especially in peripheral and interior places. Because of all these factors, most of these cases will land up in emergency cesarean sections in a very bad clinical state with delayed arrival at the higher hospitals, contributing to further increase in morbidity and mortality, as against the situation I developed countries. this can be effectively countered by improving literacy and by imparting health education to al pregnant women, to make them aware of various complications related to pregnancy and parturition to enable them to know the significance of proper antenatal care and regular checkups, better nutrition and early consultation with medical personnel in case of any complications. It is also imperative to provide better health care facilities, early referral system and better transport facilities even at remote area, in order to minimize the morbidity and mortality. ${ }^{3}$

Various factors which help to explain the increased cesarean section rate are like multiple indications; CPD, and uterine dysfunction, failed forceps deliveries, forceps deliveries are included under disproportion. Fetal distress is over three times greater as a result of improved methods of fetal heart monitoring by CTG and NST. Placental insufficiency is determined by osteriol studies, oxytocin challenge tests and human placental lactogen test. Methods for determining fetal growth and maturity, such as ultrasound, amniocentesis with certain biochemical tests, $\mathrm{Rh}$ incompatibility and presence of meconium are of great help to obstetrician in improving fetal salvage and well being. Malpresentations increase four fold in last five years the cesarean section rate. Medical indications like hypertension, diabetes, PIH, ante partum and intra-partum eclampsia, elderly primigravida, breech presentation in primigravida. History of prolonged primary infertility, failure to progress threatened rupture, CPD, Obstructed labor, placenta previa etc. 4
Fetal indications are breech, transverse lie, IUGR, oblique lie, brow and face presentation, hand and cord prolapse, compound presentations, multiple gestations with first twin vertex, persistent occipito-posterior presentation, and deep transverse arrest. $^{5}$

With a steep fall in maternal mortality and morbidity and with much more liberalization of indications, the incidence of cesarean section rate has greatly increased over the last thirty years and almost doubled in the current decade. The overall higher morbidity and mortality after emergency cesarean section than that in elective cases can be checked and reduced by efficient and sagacious management of these cases during intra and postoperative periods, because we are not left with time to improve the preoperative health situation in such emergency cases. ${ }^{5}$

Hence to review the maternal morbidity after emergency LSCS, this study was carried out.

\section{METHODS}

Hospital based prospective study conducted M. R. Medical College, Gulbarga from June 1999 to May 2000. Institutional Ethics Committee permission was taken. Informed consent was taken from all eligible participants for the present study. A total 200 women undergoing emergency lower segment cesarean section

\section{Inclusion criteria}

- The women undergoing emergency lower segment cesarean section

- Willing to participate in the present study.

\section{Exclusion criteria}

\section{- $\quad$ Presence normal delivery}

- Not willing to participate in the present study.

Data regarding age, parity, socio economic status and nutritional status was recorded and entered in the pre designed, pre tested, and semi structured study questionnaire prepared for the present study.

History of antenatal care and regular checkups, booking status (booked means at least three antenatal checkups out of which one should be in third trimester). Previous obstetric history in detail primary or repeat sections, any medical disorders complicating pregnancy like anemia, hypertension, diabetes etc. any obstetric problems like cephalo-pelvic disproportion, abrupito placenta, placenta previa, bad obstetric history, malpresentations, persistent occipito posterior, threatened rupture, obstructed labor, elderly primi, failed induction, previous LSCS, contracted pelvis, deep transverse arrest, cervical dystocia, primi with breech etc was noted and entered in the pre designed, pre tested, semi structured study questionnaire prepared for the present study. 
Fetal distress, malpresentation, compound presentations, post maturity, IUGR, Cord prolapse, twins with first other than vertex, brow etc was noted.

Indication for cesarean section, history of any premature rupture of membranes, prolonged labor, outside interventions and repeated examinations, cord prolapse, antibiotic coverage etc was noted. Intraoperative complications like anesthetic complications, hemorrhage extensions, hematomas and adhesions due to previous surgery were noted.

Post operative complications like morbidity conditions in mother like hemorrhage, pyrexia beyond 24 hours, wound sepsis and gaping, endometritis, peritonitis, paralytic ileus, urinary tract infections, mastitis, burst abdomen, VVF, prolonged hospital stay, other complications and if any requirement of blood transfusions was noted.

\section{Statistical analysis}

The data was entered in the master sheet and analyzed using proportion. Chi square value was calculated using open Epi software and p value less than 0.05 was taken as statistically significant. Odds ratio with $95 \%$ confidence interval was also calculated.

\section{RESULTS}

The incidence of LSCS during the study period was $24.21 \%$ out of 3176 total deliveries. This high incidence was attributed to more number of referral cases, better diagnostic aids and availability of improved monitoring during labor. Incidence of emergency LSCS was $96.74 \%$ out of total 769 LSCS and the incidence of elective LSCS was only $3.25 \%$. This gross increase in emergency LSCS was due to increased number of un-booked cases and delayed referral of complicated cases from peripheral centres (Table 1).

Table 1: Incidence of LSCS, emergency and elective LSCS.

\begin{tabular}{|llll|}
\hline Parameter & Number & $\%$ & $\begin{array}{l}\text { Total } \\
\text { number }\end{array}$ \\
\hline LSCS & 769 & 24.21 & 3176 \\
\hline Emergency LSCS & 744 & 96.74 & 769 \\
\hline Elective LSCS & 25 & 3.25 & 769 \\
\hline
\end{tabular}

Most of the cases i.e. $71 \%$ were having primary or the first time LSCS while $29 \%$ of the cases had second time or more i.e. repeated LSCS. Out of total 200 emergency cases 41 i.e. $20.5 \%$ were booked cases compared to a very high i.e. $159(79.5 \%)$ were un-booked cases (Table 2).

The most common maternal indication for emergency LSCS was pregnancy induced hypertension and eclampsia in $32.5 \%$ of the cases. This was followed by previous LSCS in $29 \%$, Cephalopelvic disproportion in $15 \%$, Pre-mature rupture of membranes in $15 \%$, Threatened rupture in $10 \%$, and one case was of Bad obstetric history. The most common fetal indication for emergency LSCS was fetal distress in $60 \%$ followed by malpresentation in $26 \%$, Cord prolapse in $5 \%$ of the cases (Table 3).

Table 2: Incidence of various parameters among emergency LSCS.

\begin{tabular}{|lll|}
\hline Parameter & Number & $\%$ \\
\hline Primary LSCS & 142 & 71 \\
\hline Repeated LSCS & 58 & 29 \\
\hline Booked cases & 41 & 20.5 \\
\hline Un booked cases & 159 & 79.5 \\
\hline
\end{tabular}

Table 3: Maternal and fetal indications for emergency LSCS.

\begin{tabular}{|llll|}
\hline Indications & & Number & $\%$ \\
\hline \multirow{5}{*}{ Maternal } & PIH and eclampsia & 65 & 32.5 \\
\cline { 2 - 4 } indications & Previous LSCS & 58 & 29 \\
\cline { 2 - 4 } & $\begin{array}{l}\text { Cephalopelvic } \\
\text { disproportion }\end{array}$ & 30 & 15 \\
\cline { 2 - 4 } & $\begin{array}{l}\text { Pre-mature rupture } \\
\text { of membranes }\end{array}$ & 30 & 15 \\
\cline { 2 - 4 } & Threatened rupture & 20 & 10 \\
\cline { 2 - 4 } & $\begin{array}{l}\text { Ante-partum } \\
\text { hemorrhage }\end{array}$ & 17 & 8.5 \\
\cline { 2 - 4 } & Contracted pelvis & 13 & 6.5 \\
\cline { 2 - 4 } & Obstructed labor & 6 & 3 \\
\cline { 2 - 4 } & Failed induction & 5 & 2.5 \\
\cline { 2 - 4 } & Cervical dystocia & 3 & 1.5 \\
\cline { 2 - 4 } & Elderly primi & 2 & 1 \\
\cline { 2 - 4 } Fetal & Bad obstetric history & 1 & 0.5 \\
\hline \multirow{5}{*}{ indications } & Fetal distress & 120 & 60 \\
\cline { 2 - 4 } & Malpresentation & 52 & 26 \\
\cline { 2 - 4 } & Cord prolapse & 10 & 5 \\
\cline { 2 - 4 } & Multiple pregnancy & 7 & 3.5 \\
\cline { 2 - 4 } & Post maturity & 3 & 1.5 \\
\hline
\end{tabular}

Table 4: Incidence of maternal morbidity in emergency LSCS.

\begin{tabular}{|lll|}
\hline $\begin{array}{l}\text { Total number of } \\
\text { emergency LSCS }\end{array}$ & $\begin{array}{l}\text { Number of } \\
\text { cases with } \\
\text { morbidity }\end{array}$ & $\begin{array}{l}\text { Incidence of } \\
\text { morbidity }\end{array}$ \\
\hline 200 & 70 & $35 \%$ \\
\hline
\end{tabular}

Table 4 shows incidence of maternal morbidity in cases with emergency lower segment cesarean section. There were a total of 200 cases which underwent emergency lower segment cesarean section. Out of these 200 emergency lower segment cesarean section, 70 mothers had reported some or the other form of morbidity. Thus 
the incidence of morbidity among mother of emergency lower segment cesarean section was found out to be $35 \%$.

Morbidity in the cesarean section was found to be associated with booking status, parity and social class while it was not associated with nature of cesarean section, age, and anemia. Un-booked cases were at 4.97 times more risk of having morbidity compared to those who were booked cases. Primi were found to be 2.65 times more at risk of having morbidity after emergency cesarean section compared to those with multiparity. Those belonging to low social class were 2.69 times more at risk of having morbidity compared to those who belonged to middle class (Table 5).

Table 5: Association of various factors with maternal morbidity.

\begin{tabular}{|c|c|c|c|c|c|c|c|}
\hline \multirow{2}{*}{ Factors } & & \multicolumn{2}{|c|}{ Morbidity } & \multirow[b]{2}{*}{ Chi square } & \multirow{2}{*}{$P$ value } & \multirow{2}{*}{ OR } & \multirow{2}{*}{$95 \% \mathrm{CI}$} \\
\hline & & Yes & No & & & & \\
\hline \multirow{2}{*}{ Nature of cesarean section } & Primary & 52 & 90 & \multirow[b]{2}{*}{0.3548} & \multirow{2}{*}{0.5565} & \multirow{2}{*}{1.284} & \multirow{2}{*}{$0.6685-2.466$} \\
\hline & Repeated & 18 & 40 & & & & \\
\hline \multirow{2}{*}{ Booking status } & Un-booked & 65 & 94 & \multirow{2}{*}{10.56} & \multirow{2}{*}{0.0005} & \multirow{2}{*}{4.97} & \multirow{2}{*}{$1.85-13.36$} \\
\hline & Booked & 5 & 36 & & & & \\
\hline \multirow{2}{*}{ Age (years) } & $>20$ & 62 & 118 & \multirow{2}{*}{0.061} & \multirow{2}{*}{0.4024} & \multirow{2}{*}{0.7881} & \multirow{2}{*}{$0.306-2.03$} \\
\hline & $<20$ & 8 & 12 & & & & \\
\hline \multirow{2}{*}{ Parity } & Primi & 29 & 40 & \multirow{2}{*}{9.874} & \multirow{2}{*}{0.0008} & \multirow{2}{*}{2.65} & \multirow{2}{*}{$1.47-4.78$} \\
\hline & 2 and above & 41 & 150 & & & & \\
\hline \multirow{2}{*}{ Social class } & Low & 61 & 93 & \multirow{2}{*}{5.406} & \multirow{2}{*}{0.01004} & \multirow{2}{*}{2.69} & \multirow{2}{*}{$1.21-5.98$} \\
\hline & Middle & 9 & 37 & & & & \\
\hline \multirow{2}{*}{ Anemia } & Yes & 39 & 72 & \multirow{2}{*}{0.0109} & \multirow{2}{*}{0.4584} & \multirow{2}{*}{1.01} & \multirow{2}{*}{$0.56-1.81$} \\
\hline & No & 31 & 58 & & & & \\
\hline Durtion of lobo & $>12$ hours & 29 & 30 & 61512 & 0005 & 25 & 126441 \\
\hline Duration or labor & $<12$ hours & 41 & 100 & 0.1512 & 0.005 & 2.55 & $1.20-4.41$ \\
\hline Interval between rupture of & $>12$ hours & 17 & 17 & 02723 & 03000 & 0714 & 020172 \\
\hline membranes and delivery & $<12$ hours & 20 & 28 & 0.2120 & 0.0003 & 0.114 & $0.29-1.12$ \\
\hline
\end{tabular}

Table 6: Intraoperative complications in cases undergoing emergency cesarean section.

\begin{tabular}{|lll|}
\hline Type of complication & Number & $\%$ \\
\hline Anesthetic complication & 01 & 0.5 \\
\hline Primary hemorrhage & 10 & 5 \\
\hline Extension & 10 & 5 \\
\hline Broad ligament hematoma & 02 & 1 \\
\hline Bladder injury & 02 & 1 \\
\hline Adhesions & 22 & 11 \\
\hline Total & 47 & 23.5 \\
\hline
\end{tabular}

Table 6 shows intraoperative complications in cases undergoing emergency cesarean section. Out of 200 cases undergoing emergency the incidence of intraoperative complications was seen in 47 cases i.e. $23.5 \%$ only. Adhesions were the most common complication in $11 \%$ of the cases followed by primary hemorrhage and extension in $5 \%$ of the cases each. Only one case had anesthetic complication. Two cases each had broad ligament hematoma and bladder injury.

Table 7 shows postoperative complications in cases undergoing emergency cesarean section. Majority (18.5\%) developed febrile morbidity followed by wound sepsis in $12.5 \%$, urinary tract infection in $8 \%$, mastitis in
$7.5 \%$, respiratory tract infection in $7 \%$, wound gaping in $4 \%$, paralytic ileus in $3 \%$, endometritis in $2.5 \%$, postpartum hemorrhage in $1.5 \%, 2$ cases of burst abdomen and one case of small bowel obstruction.

\section{Table 7: Postoperative complications in cases} undergoing emergency cesarean section.

\begin{tabular}{|lll|}
\hline Type of complication & Number & $\%$ \\
\hline Febrile morbidity & 37 & 18.5 \\
\hline Wound sepsis & 25 & 12.5 \\
\hline Urinary tract infection & 16 & 8 \\
\hline Mastitis & 156 & 7.5 \\
\hline Respiratory tract infection & 14 & 7 \\
\hline Wound gaping & 8 & 4 \\
\hline Paralytic ileus & 6 & 3 \\
\hline Endometritis & 5 & 2.5 \\
\hline Postpartum hemorrhage & 3 & 1.5 \\
\hline Burst abdomen & 2 & 1 \\
\hline Small bowel obstruction & 1 & 0.5 \\
\hline
\end{tabular}

\section{DISCUSSION}

Ghazi A et al, carried out a cross sectional study in Karachi. ${ }^{6}$ They found that $66 \%$ were un-booked cases. 
We also found that majority i.e. $79.6 \%$ were un-booked cases. Mean age was 28 years. In our study also majority were in the age group of 20-30 years. Multi-gravida was more than primi-gravida which is similar to the present study. Previous LSCS was the indication in $20 \%$ of the cases which is $29 \%$ as per the present study. $92 \%$ had hemorrhage during surgery which was only $5 \%$ in the present study. $80 \%$ had anesthetic complications which was only $0.5 \%$ in the present study. The authors concluded that emergency LSCS was associated with increased morbidity. ${ }^{6}$

Oladapo OT et al, carried out retrospective analysis of elective LSCS over a period of 15 years. ${ }^{7}$ The data included 164 cases and the incidence of elective LSCS was $2.4 \%$. This is similar to the findings of the present study where we found that the incidence of elective LSCS was $3.25 \%$. The authors concluded that elective LSCS was associated with increased health risk to the mothers compared to the vaginal delivery and hence vaginal delivery should be promoted. ${ }^{7}$

Liu S et al, compared elective LSCS with planned vaginal delivery outcome in a large sample. ${ }^{8}$ They found that the 14 year morbidity rate was very high i.e. 27.3 per 100 deliveries in elective LSCS group compared to only 9 per 100 deliveries in vaginal deliveries group. Hence they concluded that elective LSCS was more risky than the planned vaginal delivery and the women should consider these risks before opting for the elective LSCS. $^{8}$

Khawaja NP et al, carried out an analysis of LSCS. The incidence of LSCS was $21.1 \%$. This is quite similar to the findings of the present study that was about $24.21 \% .^{9}$ The rate of elective LSCS was $11.33 \%$ which is very high compared to the rate we found i.e. $3.25 \%$. The rate of emergency LSCS was $88.7 \%$ which is low compared to the present study rate where we noted it as $96.74 \%$. dystocia was the most common indication for emergency LSCS while in the present study, most common maternal indication for emergency LSCS was pregnancy induced hypertension and eclampsia in $32.5 \%$ of the cases. The most common fetal indication for emergency LSCS was fetal distress in $60 \%$. The incidence of maternal morbidity was $14 \%$ but in the present study we found this rate as very high i.e. $35 \% .^{9}$

Ali Y, carried out a prospective study among 100 mothers with LSCS. ${ }^{10}$ The incidence of LSCS was $8 \%$ which is very low or one third compared to the rate of $24.21 \%$ from the present study. cephalo-pelvic disproportion was the most common indication for LSCS in $44 \%$ of the cases while most common maternal indication for emergency LSCS was pregnancy induced hypertension and eclampsia in $32.5 \%$ of the cases. The most common fetal indication for emergency LSCS was fetal distress in $60 \%$. The incidence of maternal morbidity was $20 \%$ but in the present study we found this rate as very high i.e. $35 \% .^{10}$

\section{CONCLUSION}

Overall incidence of LSCS was comparatively high in the present study but the elective cesarean section rate was comparatively very low. Most cases were of emergency nature and mostly it was due to pregnancy induced hypertension and eclampsia and/or Fetal distress. Booking status, parity and social class were found to be major determinants of the morbidity among emergency LSCS cases. Emergency LSCS increased the chances of morbidity among mothers.

Funding: No funding sources

Conflict of interest: None declared

Ethical approval: The study was approved by the Institutional Ethics Committee

\section{REFERENCES}

1. Betrán AP, Merialdi M, Lauer JA, Bing-Shun W, Thomas J, Van Look P, et al. Rates of caesarean section: analysis of global, regional and national estimates. Paediatr Perinat Epidemiol. 2007;21(2):98-113.

2. Cavallaro FL, Cresswell JA, França GV, Victora CG, Barros AJ, Ronsmans C. Trends in caesarean delivery by country and wealth quintile: crosssectional surveys in southern Asia and sub-Saharan Africa. Bull World Health Organ. 2013;91(12):91422D.

3. Souza JP, Gülmezoglu A, Lumbiganon $P$, Laopaiboon M, Carroli G, Fawole B, et al. WHO global survey on maternal and perinatal health research group. Caesarean section without medical indications is associated with an increased risk of adverse short-term maternal outcomes: the 20042008 WHO Global Survey on Maternal and Perinatal Health. BMC Med. 2010;8:71.

4. Gibbons L, Belizán JM, Lauer JA, Betrán AP, Merialdi M, Althabe F. The global numbers and costs of additionally needed and unnecessary caesarean sections performed per year: overuse as a barrier to universal coverage. World Health Report. 2010;30:1-31.

5. Ajeet S, Nandkishore K. The boom in unnecessary caesarean surgeries is jeopardizing women's health. Health Care Women Int. 2013;34(6):513-21.

6. Ghazi A, Karim F, Hussain AM, Ali T, Jabbar S. Maternal morbidity in emergency versus elective cesarean section at a tertiary care hospital. J Ayub Med Coll Abbottabad. 2012;24(1):10-3.

7. Oladapo OT, Lamina MA, Sule-Odu AO. Maternal morbidity and mortality associated with elective cesarean delivery at a university hospital in Nigeria. Aust N Z J Obstet Gynecol. 2007;47(2):110-4.

8. Liu S, Liston RM, Joseph KS, Heaman M, Sauve R, Kramer MS. Maternal mortality and severe morbidity associated with low risk planned cesarean delivery versus planned vaginal delivery at term. Canadian Med Assoc J. 2007;176(4):455-60. 
9. Khawaja NP, Yousaf T, Tayyeb R. Analysis of caesarean delivery at a tertiary care hospital in Pakistan. J Obstet Gynecol. 2004;24(2):139-41.

10. Ali Y. Analysis of cesarean delivery in Jimma Hospital, south-western Ethiopia. East Afr Med J. 1995;72(1):60-3.

Cite this article as: Kalpana $\mathrm{P}$, Praveena T. Maternal morbidity in emergency lower segment cesarean section. Int J Reprod Contracept Obstet Gynecol 2019;8:2604-9. 